\title{
Surgical management for large hypertensive basal ganglionic hemorrhage: single center experience
}

\author{
Mohamed khallaf ${ }^{1 *}$ and Mohamed Abdelrahman ${ }^{2}$
}

\begin{abstract}
Purpose: We aim to summarize the role of surgical treatment of spontaneous basal ganglionic hemorrhage based on prospective analysis of our patients and determine the factors that favor the outcome.

Methods: A prospective analysis was done of 66 patients from January 2014 to June 2017. Inclusion criteria for the patients in this study were as follows: patients aged between 15 and 60 years; CT scan showed basal ganglionic hematoma with or without intraventricular extension within $24 \mathrm{~h}$ post ictus; hematoma volume was Glasgow Coma Scale (GCS) scores $\geq 5$, and stable vital signs. Surgical techniques are open craniotomy.

Results: A total of 66 patients underwent surgical intervention consisting of 47 (71.2\%) men and 19 (28.8\%) women. Their age varies from 15 to 60 with mean age \pm SD (range) $46.53 \pm 13.24$ (18.0-60.0). According to GCS, patients were categorized into three groups: GCS 5-8, 21 (31.8\%) patients; GCS 9-12, 30 (45.5\%) patients; and GCS $13-15,15$ (22.7\%) patients. The favorable outcome group was slightly younger ( $p$ value $0.050^{*}$ ). Also, the volume and extension of hematoma into the ventricular system, hydrocephalic dilatation, and midline shift greater than $5 \mathrm{~mm}$ had a significantly worse outcome with statistically significant difference.

Conclusion: The early surgical management with removal of the hematoma led to dramatic reduction of ICP and improved the prognosis. Patients with signs of brain herniation, a midline shift $>5 \mathrm{~mm}$, hydrocephalic dilatation, ventricular hemorrhage, and a depressed level of consciousness have a poor prognosis.
\end{abstract}

Trial registration: 17300234 registered 9/2018

Keywords: Spontaneous intracerebral hemorrhage, Basal ganglionic, Glasgow Coma Scale, Glasgow Outcome Score, Craniotomy

\section{Introduction}

Main text

Spontaneous intracerebral hemorrhage (ICH) is a common and often the most deadly stroke subtype. This entity accounts for 10 to $15 \%$ of all strokes [1] and is associated with a higher mortality rate ( $44 \%$ after 30 days) than either ischemic stroke or subarachnoid hemorrhage [2-4]. Long-term survivors are often saddled with permanent deficits, with up to $75 \%$ suffering significant disability and only $12 \%$ to $39 \%$ of the survivors have favorable neurological functions recovered [5]; even more long-term survival after spontaneous intracerebral hemorrhage (ICH) has been

\footnotetext{
* Correspondence: khallaf_1973@yahoo.com

'Department of Neurosurgery, Assiut University, Assiut, Egypt

Full list of author information is available at the end of the article
}

reported to be $20 \%$ to $40 \%$ at 2 years after the index stroke [6], so intracerebral hemorrhage is the subject of various studies dealing with optimal treatment.

Sixty percent of hypertensive intracerebral hemorrhage is located in the basal ganglia. The commonest etiology for such bleeds is small vessel vasculopathy secondary to chronic long-term hypertension [7]. Many observational and epidemiological studies have identified a wide range of factors that are predictive of outcome after evacuation of hematoma including age, GCS score on presentation, hematoma volume, intraventricular extension midline shift, and hydrocephalic change.

Rapid diagnosis and attentive management of patients is crucial because early deterioration is common. Neurosurgical treatment for $\mathrm{ICH}$ has been discussed in recent 
multicenter studies, but no definitive answer of its utility has emerged. Improved surgical techniques, neuroimaging, neuroanesthesia, and perioperative monitoring and care have all led to improved outcomes from surgery. The aim of this study is to present current and comprehensive recommendations for surgical treatment of this hematoma and to determine the factors that may favor the 30 days' survival rate.

\section{Patients and methods}

A single tertiary center prospective study was conducted of spontaneous basal ganglionic hemorrhage from January 2014to June 2017. All clinical records, investigations, and treatment charts were reviewed regarding age, sex, and preoperative Glasgow Coma Scale. Laboratory investigations including blood routine, coagulations studies, and biochemical examinations (e.g., hepatic, renal) were analyzed.

The CT images were evaluated and intracerebral hematoma volume was calculated by 3D Slicer Software. The lateral shift of the midline structures was measured at the level of the third ventricle. Extension of hematoma into ventricular system as well as hydrocephalic change were noted. Patients were given additional diagnostic tests such as cerebral angiography or brain magnetic resonance imaging at certain cases.

Inclusion criteria for the patients in this study were as follows: patients aged between 15 and 60 years (elderly people $>60$ years were excluded since their strokes were not routinely examined by CT scan in the emergency ward; however, in children $<15$ was due mostly to vascular malformations); CT scan showed basal ganglia hemorrhage, with or without intraventricular extension within $24 \mathrm{~h}$ post ictus, and hematoma volume was $30 \mathrm{ml}$ or above; Glasgow Coma Scale (GCS) scores $\geq 5$; and stable vital signs.

Exclusion criteria were the intracerebral hemorrhage was caused by secondary factors (e.g., vascular malformations, head injury); GCS $<5$; multiple intracranial hemorrhage; serious visceral disease (e.g., hepatic, renal) or clotting disorders; and patients with preexisting neurological deficits, e.g., previous intracerebral hematoma or infarct.

All patients received conservative treatment according to current practices. Stabilization of airway, breathing, and circulation (ABCs) is essential for preventing secondary injury from hypoxemia. Intubation is indicated in patient with GCS $\leq 8$ or significant respiratory distress, herniation syndrome, and uncontrolled seizures. Therapy included blood pressure control which is of paramount importance in patients with $\mathrm{ICH}$, hyperosmolar agents, $\mathrm{H} 2$ blockers, and nutritional support.

Indications for hematoma evacuation were made on inclusion criteria. Informed consent according to the criteria set by the local research ethics committee in our center had to be obtained in writing before surgery. If consent could not be obtained because the patient was in coma, or dysphasic, consent was obtained from relatives.

This group of patients will receive hematoma evacuation by craniotomy and was done by author neurosurgeon. All patients underwent general anesthesia and hematoma evacuation was assisted by operative microscope and evacuated as much as possible and active bleeding was controlled with standard neurosurgical techniques. The dura mater was closed and bone flap decompression was performed depending on the patients' preoperative condition and the degree of intraoperative control of cerebral pressure. Patient with a decreased level of consciousness from intraventricular hemorrhage or hydrocephalus received either external ventricular drain or shunt before or after the operation.

\section{Follow-up}

After hematoma evacuation, the patients were managed in the neurosurgical intensive care unit, and all patients were given multimodality supportive care. Postoperative systolic blood pressure must be strictly controlled, and the presence of excessive fluid was not allowed. Intense anti-edema and cerebral protectant therapy was administered during the acute phase. Nimodipine reduces vasospasm. Prophylaxis for deep vein thrombosis and physical therapy. All patients underwent a follow-up CT scan according to their neurological condition. Patients were followed for at least 6 months after treatment. The patients were classified into good or poor outcome groups based on the Glasgow Outcome Scale (GOS), with good outcome patients having a score of GOS 1 or 2 and poor outcome patients having a score of GOS 3, 4, or 5 [8].

\section{Statistical analysis}

Date entry and data analysis were done using SPSS version 19 (Statistical Package for Social Science). Data were presented as number, percentage, mean, and standard deviation. Chi-square test was used to compare between qualitative variables. $P$ value is considered statistically significant when $P<0.05$.

\section{Results}

A total of 66 patients underwent surgical intervention consisting of $47(71.2 \%)$ men and 19 (28.8\%) women. Their age varies from 15 to 60 with mean age \pm SD (range) $46.53 \pm 13.24$ (18.0-60.0). GCS score ranged between 5 and 15 and the patients were categorized into groups: GCS 5-8, 21 (31.8\%) patients; GCS 9-12, 30 (45.5\%) patients; and GCS 13-15, 15 (22.7\%) patients. The hematoma volume extended from 30 to $90 \mathrm{~cm}^{3}$ with mean \pm SD (range) $72.40 \pm 15.68$ (30.0-107.0). Intraventricular extension was recorded in 11 (16.7\%) patients while hydrocephalic dilation was observed in seven patients. Regarding midline shift, it was $<5 \mathrm{ml}$ in 30 patients 
(45.5\%) and $>5 \mathrm{ml}$ in 36 patients (54.5\%). According to GOS, 37 patients (56.1\%) showed favorable outcome, 29 (43.9\%) had a poor outcome, and 20 patients of them died with mortality rate (30.3\%) (Table 1).

The favorable outcome group was slightly younger and showed statistically significant difference compared to the unfavorable outcome group ( $p$ value $\left.0.050^{*}\right)$. In six patients less than 20 years, five (83.3\%) patients had favorable outcome in contrary to one $(16.7 \%)$ patient had a poor outcome while in older age group (41-60); 16(43.2\%) patients had favorable outcome in contrary to $21(56.2 \%)$ had a poor outcome. Regarding sex, there is no statistically significant difference between two studied groups ( $p$ value 0.849 ).

Regarding GCS at admission, there is significant statistical difference ( $p$ value $0.000^{*}$ ) between two studied groups. In 21 patients with GCS 5-8, only three (14.3\%) patients had a favorable outcome while 18 (85.7\%) showed a poor outcome. In 30 patients with GCS 9-12, $21(70 \%)$ patients had a favorable outcome while nine

Table 1 Patient demography of surgically treated spontaneous basal ganglionic hematoma

\begin{tabular}{|c|c|c|}
\hline & No. (66) & $\%$ \\
\hline \multicolumn{3}{|l|}{ Age (years) } \\
\hline$<20$ & 6 & 9.1 \\
\hline $20-40$ & 23 & 34.8 \\
\hline $41-60$ & 37 & 56.1 \\
\hline Mean \pm SD (range) & \multicolumn{2}{|c|}{$46.53 \pm 13.24(18.0-60.0)$} \\
\hline \multicolumn{3}{|l|}{ Sex } \\
\hline Male & 47 & 71.2 \\
\hline Female & 19 & 28.8 \\
\hline \multicolumn{3}{|l|}{$\begin{array}{l}\text { Preoperative neurological } \\
\text { status }\end{array}$} \\
\hline GCS 5-8 & 21 & 31.8 \\
\hline GCS 9-12 & 30 & 45.5 \\
\hline GCS 13-15 & 15 & 22.7 \\
\hline \multicolumn{3}{|l|}{$\begin{array}{l}\text { Preoperative hematoma } \\
\text { volume }\end{array}$} \\
\hline $30-60 \mathrm{ml}$ & 30 & 45.5 \\
\hline $61-90 \mathrm{ml}$ & 17 & 25.8 \\
\hline$>90 \mathrm{ml}$ & 19 & 28.8 \\
\hline Mean \pm SD (Range) & \multicolumn{2}{|c|}{$72.40 \pm 15.68(30.0-107.0)$} \\
\hline Intraventricular extension & 11 & 16.7 \\
\hline Hydrocephalic dilation & 7 & 10.6 \\
\hline \multicolumn{3}{|l|}{ Preoperative midline shift } \\
\hline$\leq 5 \mathrm{ml}$ & 30 & 45.5 \\
\hline$>5 \mathrm{ml}$ & 36 & 54.5 \\
\hline \multicolumn{3}{|l|}{ Postoperative GOS } \\
\hline G1-2 & 37 & 56.1 \\
\hline G3-5 & 29 & 43.9 \\
\hline
\end{tabular}

(30\%) showed a poor outcome. In 15 patients with GCS $13-15,13(86.7 \%)$ had a favorable outcome while two (13.3\%) had a poor outcome.

The volume of the hematoma and extension of hematoma into the ventricular system also had significant statistical difference $\left(p<0.000^{*}, 0.048^{*}\right.$; Table 2$)$. Of the 66 patients, 30 patients had a pre-evacuation hematoma (30-60 ml). Of these patients, $26(86.7 \%)$ had a good outcome (GOS 1-2) while four (13.3\%) had a poor outcome. Out of the 17 patients with large pre-evacuation hematoma (61-90), only $7(41.2 \%)$ patients had a good outcome while $10(58.8 \%)$ patients had a poor outcome. In extensive hematoma $(>90 \mathrm{ml})$, the majority of patients, 15 (78.9\%), had a poor outcome. In 11 patients with intraventricular extension, eight (72.7\%) patients had a poor outcome.

Patients with hydrocephalic dilatation of the ventricles showed a poor prognosis. Seven $(77.8 \%)$ patients had a

Table 2 Prognostic factors for surgically treated spontaneous basal ganglionic hematoma

\begin{tabular}{|c|c|c|c|c|c|}
\hline \multirow[t]{2}{*}{ Outcome } & \multicolumn{2}{|c|}{ GOS $1-2(n=37)$} & \multicolumn{2}{|c|}{ GOS $3-5(n=29)$} & \multirow[t]{2}{*}{$P$ value } \\
\hline & No. & $\%$ & No. & $\%$ & \\
\hline \multicolumn{6}{|l|}{ Age (years) } \\
\hline$<20$ & 5 & 83.3 & 1 & 16.7 & \multirow[t]{3}{*}{$0.050^{*}$} \\
\hline $20-40$ & 16 & 69.6 & 7 & 30.4 & \\
\hline $41-60$ & 16 & 43.2 & 21 & 56.8 & \\
\hline \multicolumn{6}{|l|}{ Sex } \\
\hline Male & 26 & 55.3 & 21 & 44.7 & \multirow[t]{2}{*}{0.849} \\
\hline Female & 11 & 57.9 & 8 & 42.1 & \\
\hline \multicolumn{6}{|c|}{$\begin{array}{l}\text { Neurological status } \\
\text { on admission }\end{array}$} \\
\hline GCS 5-8 & 3 & 14.3 & 18 & 85.7 & \multirow[t]{3}{*}{$0.000^{*}$} \\
\hline GCS 9-12 & 21 & 70.0 & 9 & 30.0 & \\
\hline GCS 13-15 & 13 & 86.7 & 2 & 13.3 & \\
\hline \multicolumn{6}{|c|}{ Hematoma volume } \\
\hline $30-60 \mathrm{ml}$ & 26 & 86.7 & 4 & 13.3 & \multirow[t]{3}{*}{$0.000^{*}$} \\
\hline $61-90 \mathrm{ml}$ & 7 & 41.2 & 10 & 58.8 & \\
\hline$>90 \mathrm{ml}$ & 4 & 21.1 & 15 & 78.9 & \\
\hline \multicolumn{6}{|c|}{$\begin{array}{l}\text { Intraventricular } \\
\text { extension }\end{array}$} \\
\hline Yes & 3 & 27.3 & 8 & 72.7 & \multirow[t]{2}{*}{$0.048^{*}$} \\
\hline No & 34 & 61.8 & 21 & 38.2 & \\
\hline \multicolumn{6}{|l|}{$\begin{array}{l}\text { Hydrocephalic } \\
\text { dilation }\end{array}$} \\
\hline Yes & 2 & 22.2 & 7 & 77.8 & \multirow[t]{2}{*}{$0.036^{*}$} \\
\hline No & 35 & 61.4 & 22 & 38.6 & \\
\hline \multicolumn{6}{|l|}{ Midline shift } \\
\hline$\leq 5$ & 22 & 73.3 & 8 & 26.7 & \multirow[t]{2}{*}{$0.010^{*}$} \\
\hline$>5$ & 15 & 41.7 & 21 & 58.3 & \\
\hline
\end{tabular}

* Significant 
poor prognosis with significant $p$ value $\left(0.036^{*}\right)$. Patients with a midline shift greater than $5 \mathrm{~mm}$ (36 patients) had a significantly worse outcome than 30 patients with a midline shift below $5 \mathrm{~mm}$ with $p$ value $0.010^{*}$. Only 15 patients with a midline shift above $5 \mathrm{~mm}$ had a favorable outcome (41.7\%) compared to $21(58.3 \%)$ who showed a poor outcome (Figs. 1, 2, 3, 4, and 5).

\section{Discussion}

Spontaneous supratentorial intracerebral hemorrhage $(\mathrm{SICH})$ is the second most common devastating and debilitating subtype and responsible for $9 \%$ to $27 \%$ of all strokes [9]; while the number of patients with SAH has remained stable or even decreased in the last years, the $\mathrm{ICH}$ incidence has increased globally in low-income countries, probably due to the increasing prevalence of hypertension and smoking [10].

Intracerebral hemorrhage $(\mathrm{ICH})$ is a lingering cause of significant mortality and morbidity rates in contemporary society. Case fatality rate and functional outcome of survivors are determined by the severity of the bleeding as assessed by the initial level of consciousness, volume of hematoma, and presence of intraventricular blood. Dennis et al. [11] have reported that 1-year survival rate of patients with ICH was $38 \%$ and most of the survivors are disabled. This finding is in accordance to this study where we reported the 30-day survival rate is 30.3\% which is much lower than in earlier surgical series, where it is documented as 56\% [12]. This may be explained in part by preoperative selection, improved surgical techniques, neuroimaging, neuroanesthesia, and perioperative monitoring and care which have all led to improved outcomes from surgery in many conditions.

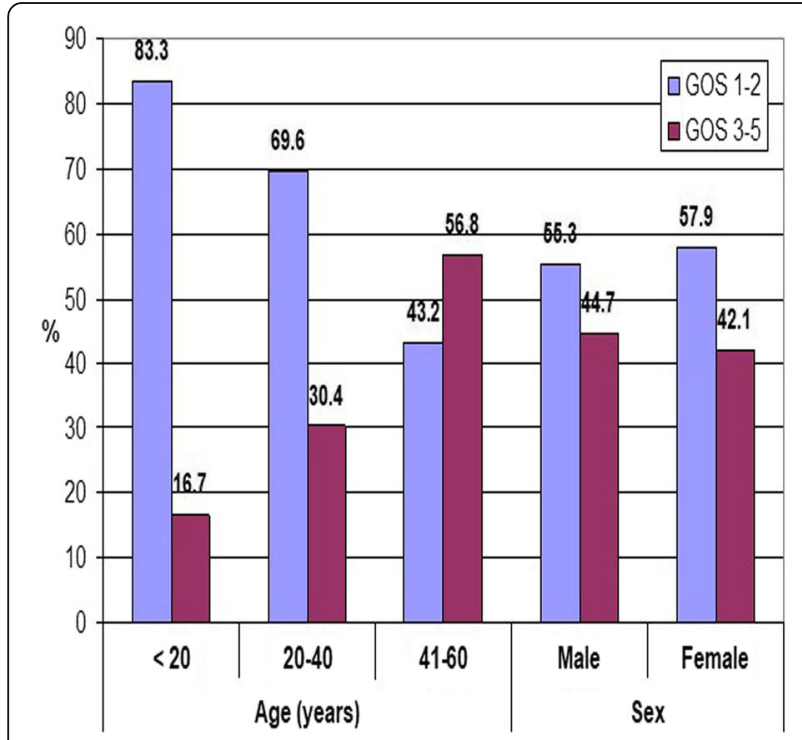

Fig. 1 Relation between age and sex to GOS

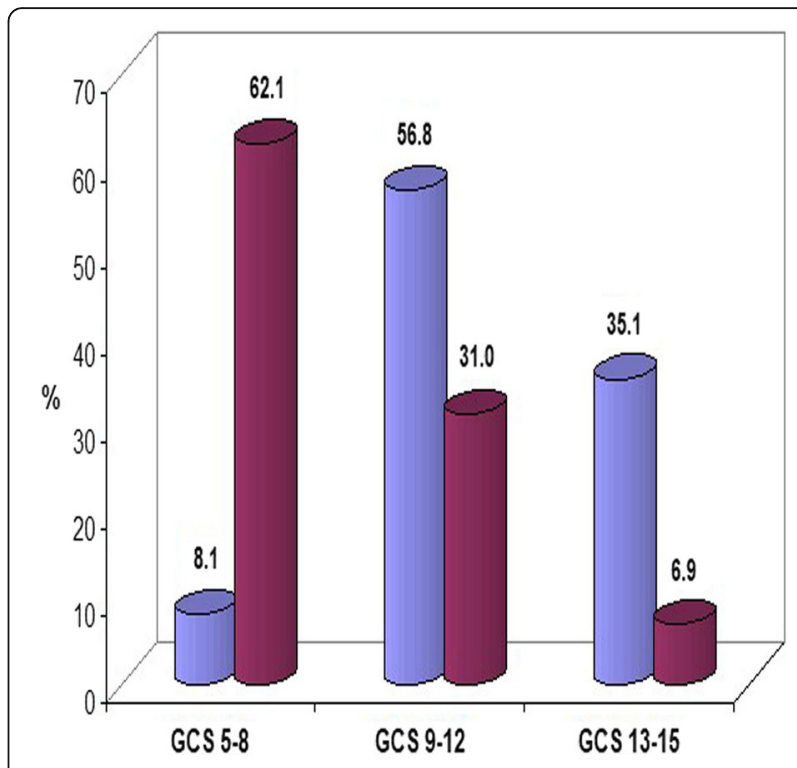

Fig. 2 Relation between GCS on admission to GOS

It is believed that the mechanism of injury in large hemorrhage is related to the mass effect and midline shift. Other postulated mechanisms include those of decreased cerebral blood flow, disruption of the blood-brain barrier, and toxicity and inflammation secondary to the breakdown products of the hematoma, such as iron and hemoglobin [13].

Management of ICH unfortunately remains heterogeneous across institutions, and it continues to suffer from the lack of proven medical and surgical effectiveness. For patients with large $\mathrm{ICH}$, comprehensive multidisciplinary

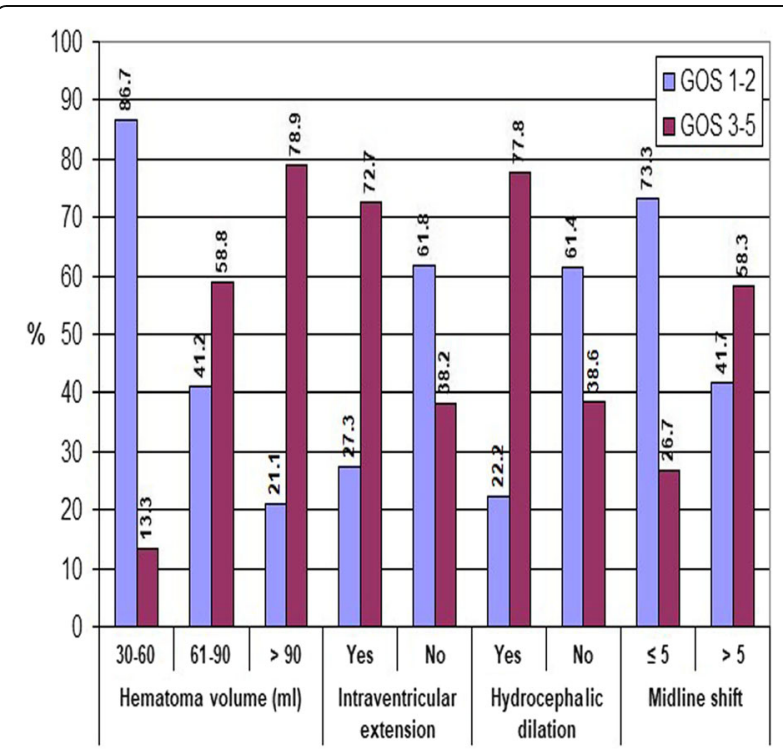

Fig. 3 Relation between hematoma volume, intraventricular extension, hydrocephalic dilation, and midline shift to GOS 

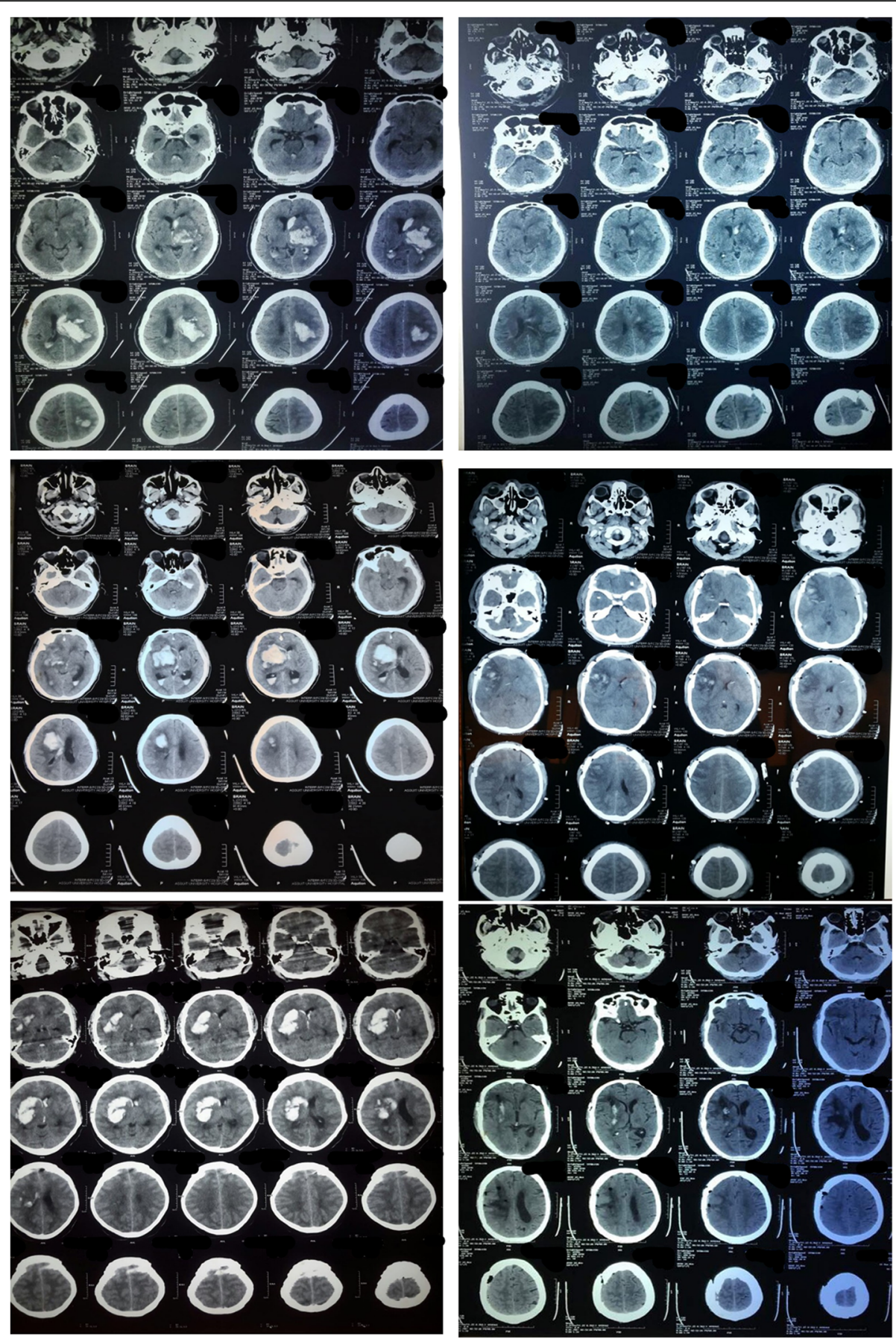

Fig. 4 Pre- and postoperative CT brain of different cases of surgically treated spontaneous basal ganglionic hematoma

care is essential to minimize morbidity and mortality. $\mathrm{ICH}$ is a medical emergency. Rapid diagnosis and attentive management of patients with ICH would intuitively appear superior and crucial because early deterioration is common in the first few hours after $\mathrm{ICH}$ onset and early hematoma evacuation can reduce both physical and chemical damage to the surrounding brain tissue [13].
A medical approach is preferred for the patients with hematoma volume $\leq 10 \mathrm{~cm}^{3}$ or for cases demonstrating minimal neurological deficit, in cases that would have very good or very poor prognosis, for cases with severe coagulopathy or presence of underlying serious medical disease, and for very old (over 80 ) cases that would not tolerate operation $[6,11,14,15]$. There was no doubt that a large life-threatening ICH should be evacuated 


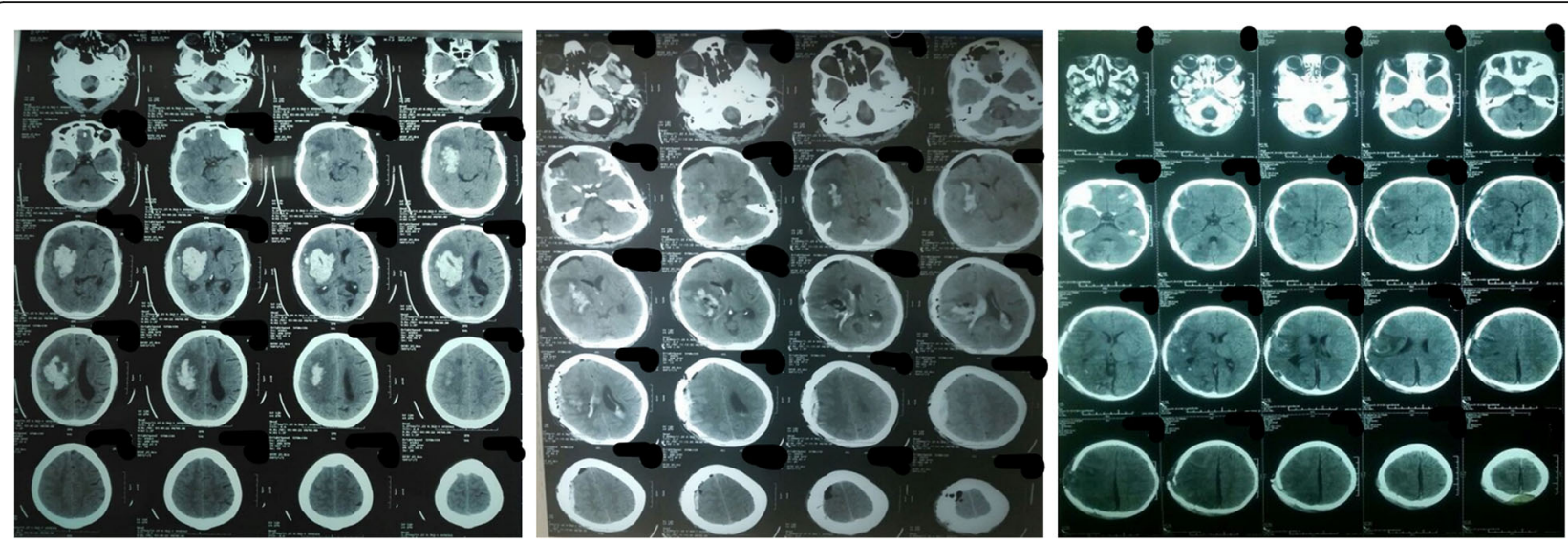

Fig. 5 Pre- and postoperative CT brain for surgically treated spontaneous basal ganglionic hematoma and developed infarction (died)

$[15,16]$. The aim of surgical treatment can be summarized briefly as removing the most hematoma volume in the fastest way and with minimum surgical damage as possible.

Recent reports have shown that the surgical methods which mainly includes craniotomy, catheter drainage, neuroendoscopy, and neuronavigation assisted surgery for SICH are safe and effective. Craniotomy is a standard approach especially for hematoma volume greater than $30 \mathrm{ml}$. It can be performed with decompressive craniectomy and duraplasty. Early hematoma evacuation may decrease the toxic effects of blood and plasma products, diminish surrounding edema and ischemia, and prevent hematoma expansion $[17,18]$. Also, the early craniotomy surgery could lead to dramatic reduction of intracranial pressure (ICP) and improvement in local blood circulation [19]. Craniotomy had also some other advantages such as good view and clearance of hematoma completely, easy hemostasis, which could help in outcomes and a reduction in mortality and improve the prognosis.

This study demonstrates the surgical outcome among patients with $\mathrm{ICH}$ following early surgery. It was found that surgery has best results among patients who are young and showed statistically significant difference compared to the unfavorable outcome group ( $p$ value $0.050 *$ ). In six patients less than 20 years, five $(83.3 \%)$ patients had favorable outcome in contrary to one $(16.7 \%)$ who had a poor outcome, while in older age group (41-60) 16 (43.2\%) patients had favorable outcome in contrary to 21 (56.2\%) who had a poor outcome.

Lampl et al. [19] found a direct correlation between the size of the hematoma, depressed level of consciousness, and outcome. Patients with relatively normal consciousness (GCS Scores 13-15) rarely require surgery, whereas deeply comatose patients (GCS Scores 3-5) rarely benefit from surgery. Surgery is therefore usually considered to have the most potential benefit for the group of patients with GCS scores between 6 and 12 or in patients with deteriorating status [2].

In this study, in the evaluation of all patients, we found a statistically significant correlation of the level of consciousness to outcome ( $p$ value $0.000 *$ ). In 21 patients with GCS 5-8, only three (14.3\%) patients had a favorable outcome while $18(85.7 \%)$ showed a poor outcome. In 30 patients with GCS 9-12, 21 (70\%) patients had a favorable outcome while nine (30. \%) showed a poor outcome. In 15 patients with GCS 13-15, 13 (86.7\%) had a favorable outcome while two (13.3\%) had a poor outcome. This finding is in accordance to Schulmeyer et al. [20]

The value of CT scan measurements in prognostication with $\mathrm{ICH}$ is well known [19]. Volume of hematoma is one of the most important parameter to evaluate the severity of the condition. Volpin et al. [21] observed in all patients with a hematoma volume above $85 \mathrm{ml}$ a lethal outcome. We also found a significant statistical correlation of hematoma size to outcome $\left(p<0.000^{*}\right.$, Table 2$)$. Of the 66 patients, 30 patients had a pre-evacuation hematoma (30$60 \mathrm{ml})$. Of these patients, $26(86.7 \%)$ had a good outcome (GOS 1-2) while four (13.3\%) had a poor outcome. Out of the 17 patients with large pre-evacuation hematoma (61$90)$, only seven $(41.2 \%)$ patients had a good outcome while ten $(58.8 \%)$ patients had a poor outcome. In extensive hematoma (>90 ml), the majority of patients, 15 (78.9\%), had a poor outcome.

ICH-related acute hydrocephalus and IVH have been found to be strong and independent predictors of poor functional outcome and mortality [22-24]. In our study, in 11 patients with intraventricular extension, eight (72.7\%) of them had a poor outcome.

The ICP was the main cause of death in patients with SICH which could increase suddenly and lead to brain herniation during the first $12 \mathrm{~h}$ [25]. ICP treatment should be directed at the underlying cause, especially if due to hydrocephalus or mass effect from 
the hematoma. Hydrocephalus is an important cause of ICH-related morbidity and mortality, and treatment should be considered in patients with decreased level of consciousness [25]. In the current study, seven (77.8\%) patients had a poor prognosis with significant $p$ value $\left(0.036^{*}\right)$. This was described by Diringer et al. [22] who found a hospital mortality of $51 \%$ in patients with hydrocephalus compared to $2 \%$ in patients without.

Patients with a midline shift greater than $5 \mathrm{~mm}$ (36 patients) had a significantly worse outcome than 30 patients with a midline shift below $5 \mathrm{~mm}$ with $p$ value $0.010^{*}$. Only 15 patients with a midline shift above $5 \mathrm{~mm}$ had a favorable outcome (41.7\%) compared to 21 (58.3\%) who showed a poor outcome. Hardemark et al. [26] recommended surgery in patients with a midline shift less than $10 \mathrm{~mm}$.

\section{Conclusion}

The efficacy of surgical hematoma evacuation for patient with basal ganglia hemorrhages compared to medical therapy remains an open debate. Evacuation should be considered in patients with large-sized basal ganglia hemorrhages, and those exhibiting progressive neurological deterioration. Patients with signs of brain herniation, a midline shift $>5 \mathrm{~mm}$, hydrocephalic dilatation of the ventricles, ventricular hemorrhage, and a depressed level of consciousness have a poor prognosis. Early surgery combined with multimodality medical management has definite positive role in the treatment of patients with spontaneous basal ganglionic hematoma.

This single center study has limitations of comparative analysis with conservative management. The sample size was not large enough to provide robust evidence for clinical practice. The strength of our study is that it was based on a defined population examined, operated and followed up by a single investigator. We included all patients with large spontaneous basal ganglionic hemorrhage admitted and operated into our hospital during the study period, without selection based on, as neither neurosurgical treatment nor neurosurgical intensive care was available in other institutions in our area.

\section{Acknowledgements}

We would acknowledge Dr. Osama Mahmoud assistant lecturer of neurosurgery in Assuit University for his efforts in data collection.

\section{Funding}

Not applicable.

\section{Availability of data and materials}

All data generated or analyzed during this study are included in this published article.

\section{Authors' contributions}

MK is the main author who contributed to the study design, analysis of patients' data, responsible of neurosurgical procedure, and writing of the publication. MA contributed to data collection. Both authors read and approved the final manuscript.

\section{Ethics approval and consent to participate}

Research committee approval has been granted for this study by the Medical Ethics Committee, Faculty of Medicine, Assiut University, with ethics committee approval number 17300234. Informed consent according to the criteria set by the local research ethics committee in our center had to be obtained in writing before surgery. If consent could not be obtained because the patient was in coma or young age ( $<18$ years), consent was obtained from relatives. Through explanation to the purpose of the study and how data will be treated with respect and confidentiality was provided to the participants.

Consent for publication

Not applicable.

\section{Competing interests}

The authors declare that they have no competing interests.

\section{Publisher's Note}

Springer Nature remains neutral with regard to jurisdictional claims in published maps and institutional affiliations.

\section{Author details}

${ }^{1}$ Department of Neurosurgery, Assiut University, Assiut, Egypt. ${ }^{2}$ Department of Neurology, Assiut University, Assiut, Egypt.

Received: 19 October 2018 Accepted: 1 May 2019

Published online: 15 May 2019

\section{References}

1. Qureshi Al, Tuhrim S, Broderick JP, Batjer HH, Hondo H, Hanley DF. Spontaneous intracerebral hemorrhage. N Engl J Med. 2001;344(19):1450-60.

2. Fernandes HM, Mendelow AD. Spontaneous intracerebral haemorrhage: a surgical dilemma. Br J Neurosurg. 1999;13(4):389-94.

3. Hemphill JC, Bonovich DC, Besmertis L, Manley GT, Johnston SC. The ICH score: a simple, reliable grading scale for intracerebral hemorrhage. Stroke. 2001;32(4):891-7.

4. Counsell C, Boonyakarnkul S, Dennis M, Sandercock P, Bamford J, Burn J, et al. Primary intracerebral haemorrhage in the Oxfordshire community stroke project. Cerebrovasc Dis. 1995;5(1):26-34.

5. Anderson CS, Huang $Y$, Wang JG, Arima H, Neal B, Peng B, et al. Intensive blood pressure reduction in acute cerebral haemorrhage trial (INTERACT): a randomised pilot trial. Lancet Neurol. 2008;7(5):391-9.

6. Kiyohara Y, Kubo M, Kato I, Tanizaki Y, Tanaka K, Okubo K, et al. Ten-year prognosis of stroke and risk factors for death in a Japanese community: the Hisayama study. Stroke. 2003;34(10):2343-7.

7. Waga S, Miyazaki M, Okada M, Tochio H, Matsushima S, Tanaka Y. Hypertensive putaminal hemorrhage: analysis of 182 patients. Surg Neurol. 1986;26(2):159-66.

8. Jennett $B$, Bond M. Assessment of outcome after severe brain damage: a practical scale. Lancet. 1975;305(7905):480-4

9. Feigin VL, Lawes CM, Bennett DA, Barker-Collo SL, Parag V. Worldwide stroke incidence and early case fatality reported in 56 population-based studies: a systematic review. Lancet Neurol. 2009;8(4):355-69.

10. Kothari RU, Brott T, Broderick JP, Barsan WG, Sauerbeck LR, Zuccarello M, et al. The ABCs of measuring intracerebral hemorrhage volumes. Stroke. 1996;27(8):1304-5.

11. Dennis MS, Burn JP, Sandercock PA, Bamford JM, Wade DT, Warlow CP. Long-term survival after first-ever stroke: the Oxfordshire community stroke project. Stroke. 1993;24(6):796-800.

12. Yilmaz C, Kabatas S, Gulsen S, Cansever T, Gurkanlar D, Caner H, et al. Spontaneous supratentorial intracerebral hemorrhage: does surgery benefit comatose patients? Ann Indian Acad Neurol. 2010;13(3):184.

13. Xi G, Keep RF, Hoff JT. Mechanisms of brain injury after intracerebral haemorrhage. Lancet Neurol. 2006;5(1):53-63.

14. MTC P, Fonville AF, Salman RA-S. Long-term prognosis after intracerebral haemorrhage: systematic review and meta-analysis. J Neurol Neurosurg Psychiatry. 2013; jnnp-2013-306476.

15. Steiner T, Al-Shahi Salman R, Beer R, Christensen H, Cordonnier C, Csiba L, et al. European stroke organisation (ESO) guidelines for the management of spontaneous intracerebral hemorrhage. Int J Stroke. 2014;9(7):840-55. 
16. Kim SH, Kim JS, Kim HY, Lee S-i. Transsylvian-transinsular approach for deepseated basal ganglia hemorrhage: an experience at a single institution. J Cerebrovasc Endovasc Neurosurg. 2015;17(2):85-92.

17. Zhou X, Chen J, Li Q, Ren G, Yao G, Liu M, et al. Minimally invasive surgery for spontaneous supratentorial intracerebral hemorrhage: a meta-analysis of randomized controlled trials. Stroke. 2012;43(11):2923-30.

18. Li Q, Yang C, Xu J, Li H, You C. Surgical treatment for large spontaneous basal ganglia hemorrhage: retrospective analysis of 253 cases. $\mathrm{Br} J$ Neurosurg. 2013;27(5):617-21.

19. Laissy J-P, Normand G, Monroc M, Duchateau C, Alibert E, Thiebot J. Spontaneous intracerebral hematomas from vascular causes. Neuroradiology. 1991;33(4):291-5

20. Lampl Y, Gilad R, Eshel Y, Sarova-Pinhas I. Neurological and functional outcome in patients with supratentorial hemorrhages: a prospective study. Stroke. 1995:26(12):2249-53.

21. Volpin L, Cervellini P, Colombo F, Zanusso M, Benedetti A. Spontaneous intracerebral hematomas: a new proposal about the usefulness and limits of surgical treatment. Neurosurgery. 1984;15(5):663-6.

22. Diringer MN, Edwards DF, Zazulia AR. Hydrocephalus: a previously unrecognized predictor of poor outcome from supratentorial intracerebral hemorrhage. Stroke. 1998;29(7):1352-7.

23. Tuhrim S, Horowitz DR, Sacher M, Godbold JH. Volume of ventricular blood is an important determinant of outcome in supratentorial intracerebral hemorrhage. Crit Care Med. 1999;27(3):617-21.

24. Witsch J, Neugebauer $H$, Zweckberger K, Jüttler E. Primary cerebellar haemorrhage: complications, treatment and outcome. Clin Neurol Neurosurg. 2013;115(7):863-9.

25. Arboix A, Comes E, García-Eroles L, Massons J, Oliveres M, Balcells M, et al. Site of bleeding and early outcome in primary intracerebral hemorrhage. Acta Neurol Scand. 2002;105(4):282-8.

26. Hårdemark H-G, Wesslén N, Persson L. Influence of clinical factors, $C T$ findings and early management on outcome in supratentorial intracerebral hemorrhage. Cerebrovasc Dis. 1999;9(1):10-21.

\section{Submit your manuscript to a SpringerOpen ${ }^{\circ}$ journal and benefit from:}

- Convenient online submission

- Rigorous peer review

- Open access: articles freely available online

High visibility within the field

- Retaining the copyright to your article

Submit your next manuscript at $\boldsymbol{\nabla}$ springeropen.com 